\title{
Expression of C-X-C chemokine receptor types 1/2 in patients with gastric carcinoma: Clinicopathological correlations and significance
}

\author{
JUN PU WANG ${ }^{1}$, WAN MING HU ${ }^{1}$, KUAN SONG WANG ${ }^{1}$, JUN YU ${ }^{2}$, BAI HUA LUO ${ }^{1}$, CHANG WU ${ }^{1}$, \\ ZHI HONG CHEN ${ }^{1}$, GENG QIU LUO ${ }^{1}$, YU WU LIU ${ }^{1}$, QIN LAI LIU ${ }^{1}$, YAN XIAO ${ }^{1}$, HAI YAN ZHOU ${ }^{1}$, \\ XIAO JING YANG ${ }^{1}$, HAI YING JIANG ${ }^{1}$, JING HE LI ${ }^{1}$ and JI FANG WEN ${ }^{1}$ \\ ${ }^{1}$ Department of Pathology, School Of Basic Medicine; ${ }^{2}$ Third Xiang-ya Hospital, \\ Central South University, Hunan, Changsha 410013, P.R. China
}

Received August 26, 2012; Accepted November 8, 2012

DOI: $10.3892 / \mathrm{ol} .2012 .1043$

\begin{abstract}
C-X-C chemokine receptor types 1/2 (CXCR1/2) may play multiple roles in the development and progression of a number of types of tumor. The abnormal expression of CXCR1/2 in various types of malignant tumors has been reported, but less is known with regard to gastric carcinoma. The present study was preliminarily conducted to elucidate the correlation between clinicopathological factors and the immunohistochemical expression of CXCR $1 / 2$ in patients with gastric carcinoma. The expression of CXCR1/2 in 69 specimens of sporadic gastric carcinoma and their corresponding non-neoplastic mucosa obtained by gastrectomy was assayed by immunohistochemistry (IHC) using a polyclonal anti-CXCR1/2 antibody. ERK1/2 and AKT phosphorylation and the expression of indicators of proliferation, growth and apoptosis (Bcl-2 and Bax, Cyclin D1, EGFR and Ki-67), angiogenesis (VEGF and CD34), invasion and metastasis (MMP-9, MMP-2, TIMP-2 and E-cadherin) were also detected by IHC. A total of 68 (98.6\%) of the 69 patients with gastric carcinoma were found to have positive CXCR1/2 expression, which appeared to be significantly higher in gastric carcinoma compared with corresponding non-neoplastic mucosa tissues. The expression of CXCR1/2 in gastric carcinoma was significantly associated with invasion, metastasis and TNM staging $(\mathrm{P}<0.001)$. Correlation analysis between CXCR1/2 and $\mathrm{pAKT}$ $(\mathrm{P}=0.032)$, pERK $(\mathrm{P}<0.001)$, Cyclin D1 $(\mathrm{P}=0.049)$, EGFR ( $\mathrm{P}=0.013), \mathrm{Bcl}-2(\mathrm{P}=0.003)$, microvessel density $(\mathrm{P}=0.001)$, MMP-9 $(\mathrm{P}=0.013)$ and MMP-2 $(\mathrm{P}=0.027)$ expression using the Spearman test showed significant correlation in gastric
\end{abstract}

Correspondence to: Dr Jing He Li, Department of Pathology, School Of Basic Medicine, Central South University, 172 Tong Zi Po Road, Hunan, Changsha 410013, P.R. China

E-mail: lijinghe0718@126.com

Key words: chemokine, C-X-C chemokine receptor types $1 / 2$, gastric carcinoma, tumor carcinoma. Univariate and multivariate logistic regression analysis showed that, compared with negative or weak expression, overexpression of CXCR $1 / 2$ protein was a significant risk factor for TNM stage $(\mathrm{P}<0.001)$. These results preliminarily suggest that CXCR1/2 may be a useful maker for progression of the tumors and a promising target for gastric carcinoma therapy.

\section{Introduction}

Gastric carcinoma is one of the most deadly types of cancer worldwide $(1,2)$, especially in China (3). Despite making advances in treatment and putting effort into research over the past few decades, the outcome of gastric cancer remains unsatisfactory, and the overall 5-year survival rate of advanced gastric adenocarcinoma patients is low. Therefore, improvement in the therapy of gastric cancer now depends on improving our understanding of the complex molecular mechanisms governing the progression and aggressiveness of the disease. Uncontrolled proliferation, invasion and metastasis as a whole is a major poor prognostic factor for advanced gastric cancer (4). It is well known that there is a close correlation between inflammation and cancer; early in 1863, Virchow hypothesized that the origin of cancer was at sites of chronic inflammation (5). Non-resolving inflammation plays a critical role in the development and progression of gastric cancer $(6,7)$, including in the dialectical correlation between inflammation and tumor progression, chemokine receptors and their ligands, an important class of non-resolving inflammatory factors, are involved in carcinogenic, proliferative, growth, invasive, metastatic and drug resistance processes (8-11).

C-X-C chemokine receptor types $1 / 2$ (CXCR1/2) belong to the chemokine receptor family, which consists of $\mathrm{G}$ proteincoupled receptors containing 7 transmembrane domains. CXCR1/2 are receptors for interleukin-8 (IL-8) and transduce the signal through a $\mathrm{G}$ protein-activating second messenger system. CXCR1 and CXCR2 proteins have a single polypeptide chain which is 350 and 355 or 360 amino acids in length, respectively, which share $76 \%$ amino acid identity to one another with the highest homology over the membrane- 
spanning regions and significant divergence at both $\mathrm{N}$ - and C-termini $(12,13)$. CXCR1/2 are expressed mainly on neutrophils and were originally characterized by their ability to induce the chemotaxis of leukocytes. Recently, it was found that CXCR1/2 are overexpressed in numerous solid tumors, and the studies revealed a close correlation with proliferation, angiogenesis, invasion, metastasis and drug resistance of the tumor (14-19). Although there have been some studies on CXCR1/2 in several cancer types and there have been a few reports on the role of CXCR1/2 in gastric carcinoma (20), to date, the significance of CXCR $1 / 2$ expression in gastric cancer progression has not been evaluated in detail.

To determine the functional role of CXCR $1 / 2$ in the progression of gastric carcinoma, based on the literature review and our previous study (21), in the present study, we investigated CXCR1/2 expression in tumors of patients diagnosed with primary gastric carcinoma and in corresponding non-neoplastic mucosa. We preliminarily discuss the correlation between the immunohistochemical expression of CXCR1/2 and clinicopathological features, phosphorylation of ERK1/2 and AKT and the expression of relevant indicators of proliferation, growth and apoptosis (Bcl-2, Bax, Cyclin D1, EGFR and Ki-67), angiogenesis (VEGF and CD34), invasion and metastasis (MMP-9, MMP-2, TIMP-2 and E-cadherin).

\section{Materials and methods}

Patients and specimens. This study was conducted on 69 primary and sporadic gastric adenocarcinoma tissue samples and their corresponding non-neoplastic mucosa specimens retrieved from the archives at the Department of Pathology of Xiang-ya Hospital of Central South University (Changsha, China) between 2008 and 2010. The protocol followed the ethical guidelines of the Declaration of Helsinki, and informed consent was obtained from all patients before the study. No patients had received chemotherapy or radiotherapy prior to surgery. Tissue blocks of non-neoplastic mucosa ( $>5 \mathrm{~cm}$ away from the edge of tumor) were obtained. The clinicopathological findings were determined according to the AJCC tumor-node-metastasis (TNM) staging system (22). The patients' data and histopathological characteristics of the tumors are summarized in Table I.

Antibodies. Phosphorylated antibodies (pAKT-Ser ${ }^{473}$, antiAKT, pERK-Thr ${ }^{202} / \mathrm{Tyr}^{204}$ and anti-ERK) were obtained from Anbo Biotechnology Co., Ltd. (San Francisco, CA, USA) and the following antibodies were purchased from Santa Cruz Biotechnology, Inc. (Santa Cruz, CA, USA): CXCR1/2, Bcl-2, Bax, Cyclin D1, EGFR, Ki-67, VEGF, CD34, MMP-9, MMP-2, TIMP-2 and E-cadherin. The StreptAvidin Biotin Complex (SABC) kit (Wuhan Boster Bio-Engineering Ltd. Co., China) was used according to the manufacturer's instructions.

Immunohistochemical analysis. Immunohistochemistry (IHC) was performed as previously described (21). More than 10 serial thin $(4 \mu \mathrm{m})$ sections were cut from each paraffin block. The sections were deparaffinized and endogenous peroxidase activity was blocked. The sections were then pretreated in antigen retrieval buffer (citrate buffer, $\mathrm{pH}$ 6.0, at $100^{\circ} \mathrm{C}, 2 \mathrm{~min}$ in a pressure cooker) and stained with primary antibodies CXCR1/2, pAKT-Ser ${ }^{473}$, AKT, pERK-Thr ${ }^{202} / \mathrm{Tyr}^{204}$, ERK, Bcl-2, Bax, Cyclin D1, EGFR, Ki-67, VEGF, CD34, MMP-9, MMP-2, TIMP-2 and E-cadherin (diluted 1:200). IgG2b-stained sections were used as negative controls. Slides were then washed and incubated for $1 \mathrm{~h}$ with the appropriate horseradish peroxidase-conjugated secondary antibody. Diaminobenzidine (DAB) was used as the chromogen and sections were counterstained with hematoxylin.

Clinicopathological and immunohistochemical assessment. The tumors were staged by two observers who had no prior knowledge of the results of the assays, according to the 7 th edition of the AJCC tumor-node-metastasis (TNM) classifications. The immunohistochemical expression of the indicators was independently assessed by two pathologists, without knowledge of the clinical data. The distribution of the immunohistochemical expression of the indicators was semi-quantitatively assessed by estimating the proportion and intensity of positively stained tumor cells. According to previous studies $(23,24)$, in brief, the adjusted Allred scoring system was applied to evaluate each entire slide using light microscopy. First, the proportion score (PS) was assigned using a 0 -to- 4 scale: 0 for $0-5 \%$ positive tumor cells, 1 for $6-25 \%$ positive tumor cells, 2 for $26-50 \%$ positive tumor cells, 3 for $51-75 \%$ positive tumor cells and 4 for $>75 \%$ positive tumor cells. The intensity score (IS) was based on a 4-point system: 0, 1, 2 and 3 (for no, light, medium or dark staining, respectively). The proportion and intensity scores were added to obtain a total score. When a total score was 0 or 1 , the intensity of immunostaining in the tissue was considered negative; the intensity was weak when a total score was between 2 and 4 ; and the intensity was strong when a total score was $\geq 5$. Clinicopathological factors, including age, gender, staging, ERK1/2 and AKT phosphorylation and the expression of indicators of proliferation, growth and apoptosis (Bcl-2, Bax, Cyclin D1, EGFR and Ki-67), angiogenesis (VEGF and CD34), invasion and metastasis (MMP-9, MMP-2, TIMP-2 and E-cadherin) were analyzed for an association with CXCR1/2 expression.

Statistical analysis. The SPSS 13.0 software system (SPSS, Inc., Chicago, IL, USA) was used for statistical analysis. The Spearman correlation was used, when appropriate, to analyze the significance of the correlation between CXCR1 protein expression and tumor characteristics, including age, gender, staging, ERK1/2 and AKT phosphorylation and expression of indicators of proliferation, growth and apoptosis, invasion and metastasis. Uni- and multivariate logistic regression analysis was performed to determine factors associated with tumor stage. $\mathrm{P}<0.05$ was considered to indicate a statistically significant result.

\section{Results}

Association between CXCR1/2 expression and clinicopathological factors of gastric carcinoma. Positive staining for CXCR1/2 was shown in $68(98.6 \%)$ of the 69 tumor specimens (Table II). CXCR1/2 showed membrane and cytoplasmic expression in tumor cells and also in some leukocytes and vascular endothelial cells (Fig. 1). Based on CXCR1/2 expres- 
Table I. Patient data and tumor characteristics.

\begin{tabular}{|c|c|}
\hline Factor & Value \\
\hline No. of patients & 69 \\
\hline \multicolumn{2}{|l|}{ Gender, n (\%) } \\
\hline Male & $55(73.5)$ \\
\hline Female) & $14(26.5)$ \\
\hline Age (years), median (range) & $55(31-79)$ \\
\hline \multicolumn{2}{|l|}{ TNM stage, n (\%) } \\
\hline \multicolumn{2}{|l|}{ T stage } \\
\hline $\mathrm{T} 1$ & $3(4.3)$ \\
\hline $\mathrm{T} 2$ & $13(18.8)$ \\
\hline $\mathrm{T} 3$ & $36(52.2)$ \\
\hline $\mathrm{T} 4$ & $17(24.6)$ \\
\hline \multicolumn{2}{|l|}{ N stage } \\
\hline N0 & $22(31.9)$ \\
\hline N1 & $21(30.4)$ \\
\hline $\mathrm{N} 2$ & $12(17.4)$ \\
\hline N3 & $14(20.3)$ \\
\hline \multicolumn{2}{|l|}{ Overall stage } \\
\hline I & $8(11.6)$ \\
\hline II & $33(47.8)$ \\
\hline III & $27(39.1)$ \\
\hline IV & $1(1.4)$ \\
\hline \multicolumn{2}{|l|}{ Differentiation } \\
\hline Good & $7(10.1)$ \\
\hline Moderate & $24(34.8)$ \\
\hline Poor & $38(55.1)$ \\
\hline
\end{tabular}

sion levels, demographic characteristics and tumor status were analyzed (Table II). Table II shows that as CXCR1/2 expression increased in the tumor, so did the overall tumor stage. Of 68 tumors with positive CXCR1/2 expression, 60 $(88.2 \%)$ cases were stage II, III and IV, but only 8 (11.8\%) were stage I. According to the evaluation of the CXCR1/2 immnunostaining, CXCR1/2 expression was significantly correlated with TNM stage, $\mathrm{T}$ stage and $\mathrm{N}$ stage $(\mathrm{P}<0.001)$. However, no correlation was observed between $\mathrm{CXCR} 1 / 2$ expression and gender, age and tumor differentiation.

Association between expression of CXCRI/2 and indicators of phosphorylation, proliferation, growth, apoptosis, angiogenesis, invasion and metastasis. Correlation analysis between the expression of CXCR $1 / 2$ and the indicators of phosphorylation (AKT, ERK, pAKT and pERK), proliferation, growth and apoptosis (Bcl-2, Bax, Cyclin D1, EGFR and Ki-67), angiogenesis (VEGF and CD34), invasion and metastasis (MMP-9, MMP-2, TIMP-2 and E-cadherin) using the Spearman correlation test revealed that CXCR1/2 expression was significantly correlated with pAKT, pERK, Cyclin D1, EGFR, Bcl-2, microvessel density (MVD), MMP-9 and MMP-2 $(\mathrm{P}=0.032, \mathrm{P}<0.001, \mathrm{P}=0.049, \mathrm{P}=0.013, \mathrm{P}=0.003$,
Table II. Association between the expression of CXCR1/2 and clinicopathological factors of gastric carcinoma.

\begin{tabular}{|c|c|c|c|c|}
\hline \multirow[b]{2}{*}{ Characteristics } & \multicolumn{3}{|c|}{ Expression } & \multirow[b]{2}{*}{ P-value } \\
\hline & $\begin{array}{c}\text { Negative } \\
\quad(n=1)\end{array}$ & $\begin{array}{l}\text { Weak } \\
(n=45)\end{array}$ & $\begin{array}{l}\text { Strong } \\
(n=23)\end{array}$ & \\
\hline Male:female & $0: 1$ & $37: 8$ & $18: 5$ & 0.452 \\
\hline $\begin{array}{l}\text { Age (years), } \\
\text { mean } \pm \mathrm{SD}\end{array}$ & $53.0 \pm 0$ & $52.3 \pm 20.0$ & $56.0 \pm 27.3$ & 0.501 \\
\hline $\begin{array}{l}\text { Cancer cell } \\
\text { differentiation }\end{array}$ & & & & 0.357 \\
\hline Good & 0 & 5 & 2 & \\
\hline Moderate & 0 & 17 & 7 & \\
\hline Poor & 1 & 23 & 14 & \\
\hline $\mathrm{T}$ stage & & & & $<0.001$ \\
\hline $\mathrm{T} 1$ & 0 & 3 & 0 & \\
\hline $\mathrm{T} 2$ & 0 & 13 & 0 & \\
\hline T3 & 1 & 20 & 15 & \\
\hline $\mathrm{T} 4$ & 0 & 9 & 8 & \\
\hline N stage & & & & $<0.001$ \\
\hline N0 & 1 & 20 & 1 & \\
\hline $\mathrm{N} 1$ & 0 & 17 & 4 & \\
\hline $\mathrm{N} 2$ & 0 & 7 & 5 & \\
\hline N3 & 0 & 1 & 13 & \\
\hline Overall stage & & & & $<0.001$ \\
\hline $\mathrm{I}$ & 0 & 8 & 0 & \\
\hline II & 1 & 30 & 2 & \\
\hline III & 0 & 6 & 21 & \\
\hline IV & 0 & 1 & 0 & \\
\hline
\end{tabular}

CXCR1/2, C-X-C chemokine receptor types $1 / 2$.

$\mathrm{P}=0.001, \mathrm{P}=0.013$ and $\mathrm{P}=0.027$, respectively), but $\mathrm{CXCR} 1 / 2$ and AKT, ERK, Ki-67, Bax, VEGF, TIMP-2 and E-cadherin expression were not significantly correlated in gastric carcinoma (Fig. 2 and Table III).

Association between expression of $p A K T$ and $p E R K$ and indicators of proliferation, growth, apoptosis, angiogenesis, invasion and metastasis. Positive immunohistochemical reaction for AKT, pAKT, ERK and pERK in tumor cells was characterized by positive staining in the membrane and cytoplasm (Fig. 2A-D). Based on the immnunostaining evaluation, the expression of pAKT was significantly correlated with Ki-67, EGFR, Bcl-2, VEGF and MMP-2 expression ( $\mathrm{P}=0.001$, $\mathrm{P}=0.029, \mathrm{P}<0.001, \mathrm{P}=0.003$ and $\mathrm{P}=0.041$, respectively), but not with Cyclin D1, Bax, MVD, MMP-9, TIMP-2 and E-cadherin expression. pERK expression was significantly correlated with Ki-67, EGFR, Bcl-2, MMP-9 and MMP-2 expression $(\mathrm{P}=0.013, \mathrm{P}=0.002, \mathrm{P}<0.001, \mathrm{P}=0.003$ and $\mathrm{P}=0.010$, respectively), and tended to correlate with Cyclin D1, Bax, MVD and TIMP-2 expression $(\mathrm{P}=0.098, \mathrm{P}=0.081, \mathrm{P}=0.073$ and $\mathrm{P}=0.084$, respectively), but not with $\mathrm{VEGF}$ and E-cadherin expression (Table IV). 
Table III. Association between the expression of CXCR1/2 and indicators of proliferation, growth, apoptosis, angiogenesis, invasion and metastasis.

\begin{tabular}{lcccc}
\hline & \multicolumn{3}{c}{ CXCR1/2 expression } & \\
\cline { 2 - 4 } $\begin{array}{l}\text { Indicator } \\
\text { expression }\end{array}$ & $\begin{array}{c}\text { Negative } \\
(\mathrm{n}=1)\end{array}$ & $\begin{array}{l}\text { Weak } \\
(\mathrm{n}=45)\end{array}$ & $\begin{array}{c}\text { Strong } \\
(\mathrm{n}=23)\end{array}$ & P-value \\
\hline
\end{tabular}

Phosphorylation

AKT

Negative

Weak

Strong

pAKT

Negative

Weak

Strong

ERK

Negative

Weak

Strong

pERK

Negative

Weak

Strong

Proliferation and growth

Ki-67

Negative

Weak

Strong

Cyclin D1

Negative

Weak

Strong

EGFR

Negative

Weak

Strong

Apoptosis

Bcl-2

Negative

Weak

Strong

Bax

Negative

Weak

Strong

Angiogenesis

VEGF

Negative

Weak

Strong
0.339

0

13

10

$15 \quad 10$

0.032

11

$15 \quad 6$

$29 \quad 16$

16

$0 \quad 0$

9

36

6

17

\section{2}

$<0.001$

$$
0
$$$$
1
$$

0.725$$
<0.001
$$$$
0
$$

2

Table III. Continued.

\begin{tabular}{|c|c|c|c|c|}
\hline \multirow[b]{2}{*}{$\begin{array}{l}\text { Indicator } \\
\text { expression }\end{array}$} & \multicolumn{3}{|c|}{ CXCR1/2 expression } & \multirow[b]{2}{*}{ P-value } \\
\hline & $\begin{array}{l}\text { Negative } \\
\quad(n=1)\end{array}$ & $\begin{array}{l}\text { Weak } \\
(n=45)\end{array}$ & $\begin{array}{l}\text { Strong } \\
(n=23)\end{array}$ & \\
\hline MVD & & & & 0.001 \\
\hline$<20$ & 1 & 31 & 9 & \\
\hline$\geq 20$ & 0 & 14 & 14 & \\
\hline \multicolumn{5}{|c|}{$\begin{array}{l}\text { Invasion } \\
\text { and metastasis }\end{array}$} \\
\hline MMP-9 & & & & 0.013 \\
\hline Negative & 1 & 11 & 1 & \\
\hline Weak & 0 & 29 & 16 & \\
\hline Strong & 0 & 5 & 6 & \\
\hline MMP-2 & & & & 0.027 \\
\hline Negative & 1 & 14 & 6 & \\
\hline Weak & 0 & 30 & 15 & \\
\hline Strong & 0 & 1 & 2 & \\
\hline TIMP-2 & & & & 0.843 \\
\hline Negative & 0 & 24 & 11 & \\
\hline Weak & 1 & 21 & 11 & \\
\hline Strong & 0 & 0 & 1 & \\
\hline E-cadherin & & & & 0.414 \\
\hline Negative & 0 & 12 & 4 & \\
\hline Weak & 1 & 28 & 17 & \\
\hline Strong & 0 & 5 & 2 & \\
\hline
\end{tabular}

0.456

Tumor samples of patients were divided into negative, weak and positive groups of immunohistochemical expression. The tumor samples were divided into high and low MVD groups assessed with the mean microvessel density value of 20 as the cut-off value. CXCR $1 / 2$,

0.049 C-X-C chemokine receptor types $1 / 2$; MVD, microvessel density.

0.013 Factors associated with tumor stage. Based on a univariate analysis, CXCR1/2, pERK and MVD expression were significantly associated with high TNM stage, and the odds ratios (ORs) were 39.291, 5.186 and 13.383, respectively, which suggested that cases with strong CXCR1 expression, strong ERK phosphorylation and high MVD had a 39.291-, 5.186- and $0.003 \quad 13.383$-fold higher risk for high TNM stage, compared with negative and weak CXCR1 expression and ERK phosphorylation and low MVD, respectively. The other detected indicators were not significantly associated with high TNM stage. The multivariate analysis indicated that only CXCR1/2 and MVD expression were significantly associated with high TNM stage, with ORs of 204.793 and 28.905, respectively (Table V).

A univariate analysis showed that poor tumor differentiation, strong CXCR1/2 expression and high MVD were significant risk factors for T stage, with ORs of 3.534 (1/0.283), 4.039 and 3.855, respectively. Tumor differentiation, 0.678 CXCR1/2, pAKT, Ki-67 and EGFR expression were associated with high $\mathrm{T}$ stage by the multivariate analysis (Table VI). A univariate analysis indicated that CXCR1/2, pERK, EGFR and MVD expression were significant risk factors for T stage; 
Table IV. Association between the expression of indicators of phosphorylation and those of proliferation, growth, apoptosis, angiogenesis, invasion and metastasis.

\begin{tabular}{|c|c|c|c|c|}
\hline \multirow[b]{2}{*}{ Indicator expression } & \multicolumn{4}{|c|}{ P-value } \\
\hline & AKT & pAKT & ERK & pERK \\
\hline \multicolumn{5}{|c|}{ Proliferation and growth } \\
\hline Ki-67 & 0.125 & 0.001 & 0.020 & 0.013 \\
\hline Cyclin D1 & 0.889 & 0.349 & 0.596 & 0.098 \\
\hline EGFR & 0.296 & 0.029 & 0.370 & 0.002 \\
\hline \multicolumn{5}{|l|}{ Apoptosis } \\
\hline Bcl-2 & 0.051 & $<0.001$ & 0.003 & $<0.001$ \\
\hline Bax & 0.031 & 0.451 & 0.012 & 0.081 \\
\hline \multicolumn{5}{|l|}{ Angiogenesis } \\
\hline VEGF & 0.086 & 0.003 & 0.048 & 0.102 \\
\hline MVD & 0.079 & 0.841 & 0.560 & 0.073 \\
\hline \multicolumn{5}{|c|}{ Invasion and metastasis } \\
\hline MMP-9 & 0.427 & 0.161 & 0.275 & 0.003 \\
\hline MMP-2 & 0.572 & 0.041 & 0.086 & 0.010 \\
\hline TIMP-2 & 0.167 & 0.456 & 0.587 & 0.084 \\
\hline E-cadherin & 0.014 & 0.202 & 0.110 & 0.391 \\
\hline
\end{tabular}

Table V. Univariate and multivariate analyses of clinicopathological variables and the expression of CXCR1/2 with regard to TNM stage.

\begin{tabular}{|c|c|c|c|c|c|c|}
\hline \multirow[b]{2}{*}{ Variables } & \multicolumn{3}{|c|}{ Univariate analysis } & \multicolumn{3}{|c|}{ Multivariate analysis } \\
\hline & OR & $95 \% \mathrm{CI}$ & P-value & OR & $95 \% \mathrm{CI}$ & P-value \\
\hline Gender (male vs. female) & 0.754 & $0.246-2.312$ & 0.062 & 0.610 & $0.074-5.053$ & 0.646 \\
\hline Age (<60 vs. $\geq 60$ years $)$ & 1.022 & $0.405-2.581$ & 0.963 & 0.806 & $0.167-3.900$ & 0.789 \\
\hline Differentiation (poor vs. moderate, good) & 0.570 & $0.229-1.422$ & 0.228 & 0.549 & $0.108-2.804$ & 0.471 \\
\hline CXCR1/2 (negative, weak vs. strong) & 39.291 & 9.061-169.864 & $<0.001$ & 204.793 & $14.850-2827.081$ & $<0.001$ \\
\hline pAKT (negative, weak vs. strong) & 1.193 & $0.412-3.463$ & 0.744 & 5.435 & $0.775-38.081$ & 0.089 \\
\hline pERK (negative, weak vs. strong) & 5.186 & $1.786-15.059$ & 0.002 & 2.049 & $0.336-12.516$ & 0.437 \\
\hline Ki-67 (negative, weak vs. strong) & 1.111 & $0.400-3.089$ & 0.840 & 0.849 & $0.082-8.837$ & 0.891 \\
\hline Cyclin D1 (negative, weak vs. strong) & 1.506 & $0.474-4.783$ & 0.488 & 1.563 & $0.166-14.688$ & 0.697 \\
\hline EGFR (negative, weak vs. strong) & 1.091 & $0.357-3.330$ & 0.879 & 0.149 & $0.013-1.766$ & 0.131 \\
\hline Bcl-2 (negative, weak vs. strong) & 1.560 & $0.631-3.857$ & 0.336 & 3.436 & $0.481-24.582$ & 0.219 \\
\hline Bax (negative, weak vs. strong) & 1.127 & $0.315-4.039$ & 0.854 & 0.677 & $0.071-6.449$ & 0.734 \\
\hline VEGF (negative, weak vs. strong) & 0.604 & $0.242-1.507$ & 0.280 & 0.499 & $0.072-3.483$ & 0.483 \\
\hline MVD (<20 vs. $\geq 20)$ & 13.383 & $4.280-41.846$ & $<0.001$ & 28.905 & $4.092-204.384$ & 0.001 \\
\hline MMP-9 (negative, weak vs. strong) & 0.988 & $0.290-3.367$ & 0.985 & 0.288 & $0.020-4.166$ & 0.361 \\
\hline MMP-2 (negative, weak vs. strong) & 0.419 & $0.045-3.881$ & 0.443 & 0.260 & $0.003-26.050$ & 0.566 \\
\hline E-cadherin (negative, weak vs. strong) & 0.245 & $0.052-1.121$ & 0.075 & 0.067 & $0.003-1.697$ & 0.101 \\
\hline
\end{tabular}

Patients were divided into two groups of age assessed with 60 years as the cut-off value. CXCR1/2, C-X-C chemokine receptor types $1 / 2$; OR, odds ratio; MVD, microvessel density; $95 \%$ CI, 95\% confidence interval.

and the significance of CXCR1/2, pERK, EGFR, VEGF and MVD expression was preserved using multivariate analysis (Table VII). Taken together, strong CXCR $1 / 2$ expression is a significant risk factor for $\mathrm{T}$ stage, $\mathrm{N}$ stage and TNM stage in gastric carcinoma.

\section{Discussion}

Previous studies have shown that cancer cells from numerous types of cancer express higher levels of the chemokine receptors (25-27). Chemokine receptors and their ligands were 


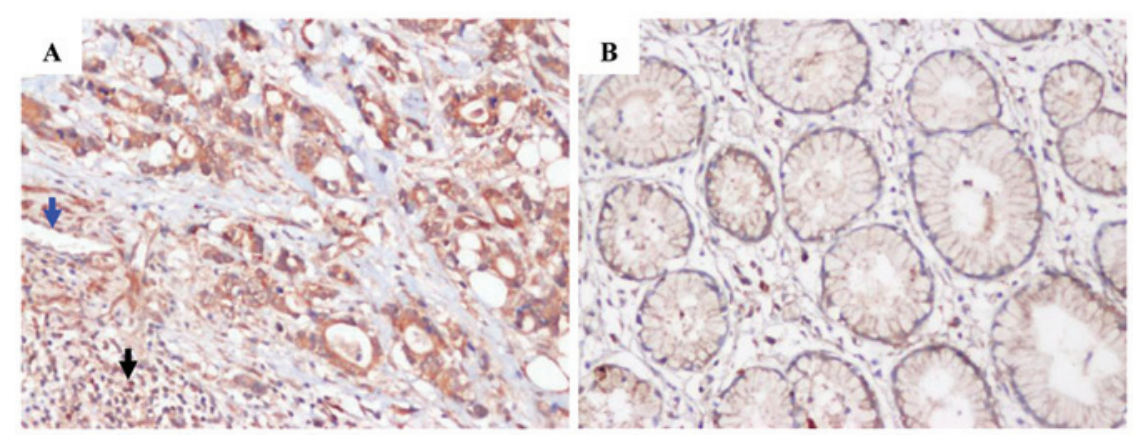

Figure 1. Representative immunohistochemical staining for CXCR1/2 in corresponding non-neoplastic mucosa tissue and tumor. (A) Tumor tissue with strong expression. CXCR1/2 were also present in some leukocytes (black arrowhead) and vascular endothelial cells (blue arrowhead). (B) Corresponding non-neoplastic mucosa tissue. Original magnification, x200. IgG stainingwas used as a negative control. CXCR1/2, C-X-C chemokine receptor types $1 / 2$.

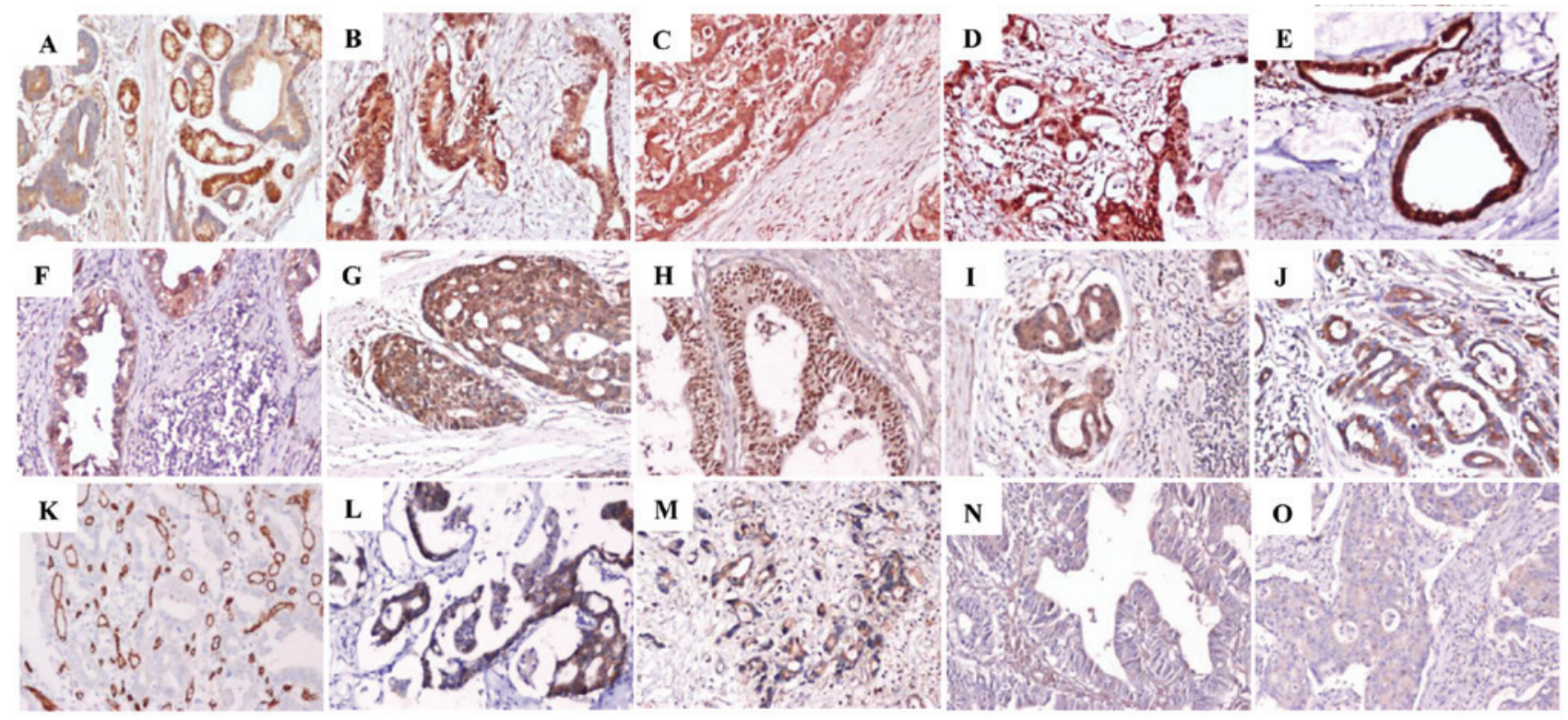

Figure 2. In gastric carcinoma, representative immunostaining for phosphorylation indicators: (A) AKT, (B) pAKT, (C) ERK, (D) pERK; proliferation, growth and apoptosis indicators: (E) Bcl-2, (F) Bax, (G) Ki-67, (H) Cyclin D1, (I) EGFR; angiogenesis indicators: (J) VEGF, (K) CD34 to calculate microvessel density; invasion and metastasis indicators: (L) MMP-2, (M) MMP-9, (N) TIMP-2, (O) E-cadherin. Original magnification, x200. IgG staining was used as a negative control.

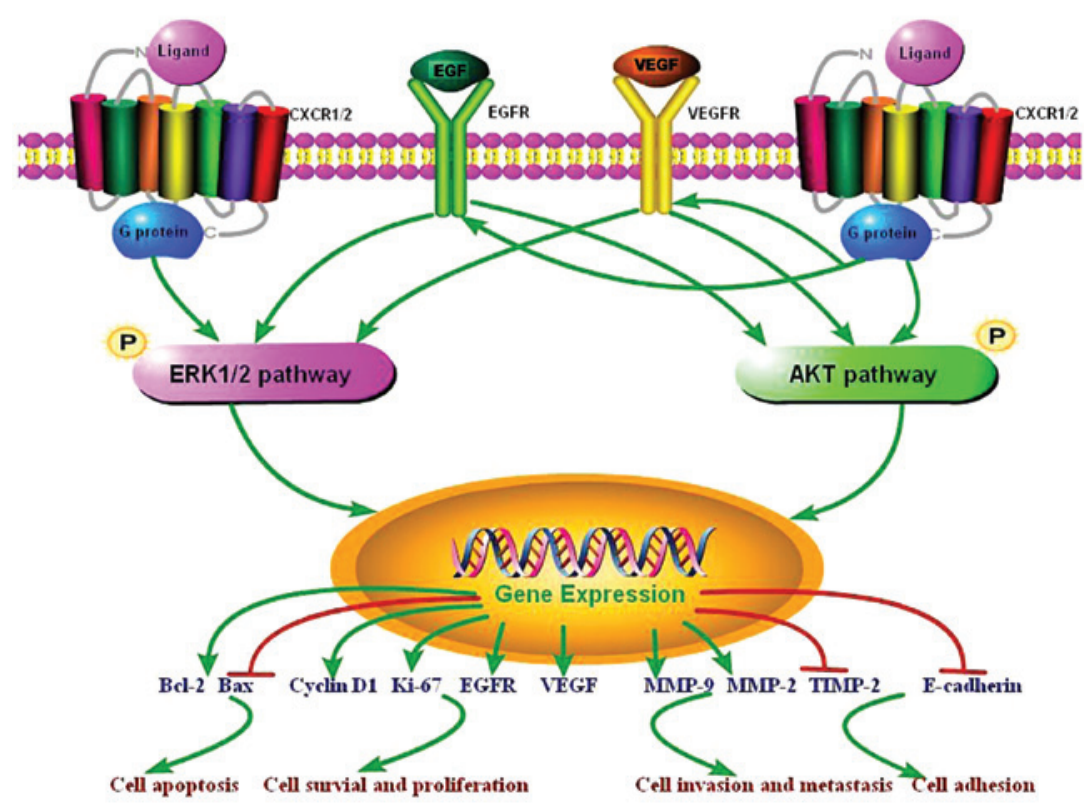

Figure 3. CXCR1/2 receptor/ligand signaling pathways in gastric carcinoma. CXCR1/2, C-X-C chemokine receptor types 1/2. 
Table VI. Uni- and multivariate analyses of clinicopathological variables and the expression of CXCR $1 / 2$ with regard to $\mathrm{T}$ stage.

\begin{tabular}{|c|c|c|c|c|c|c|}
\hline \multirow[b]{2}{*}{ Variables } & \multicolumn{3}{|c|}{ Univariate analysis } & \multicolumn{3}{|c|}{ Multivariate analysis } \\
\hline & OR & $95 \% \mathrm{CI}$ & P-value & OR & $95 \% \mathrm{CI}$ & P-value \\
\hline Differentiation (poor vs. moderate, good) & 0.283 & $0.108-0.745$ & 0.011 & 0.268 & $0.072-0.997$ & 0.049 \\
\hline CXCR1/2 (negative, weak vs. strong) & 4.039 & $1.448-11.257$ & 0.008 & 8.101 & $1.861-35.269$ & 0.005 \\
\hline pAKT (negative, weak vs. strong) & 1.579 & $0.614-4.063$ & 0.343 & 5.382 & $1.203-24.095$ & 0.028 \\
\hline Ki-67 (negative, weak vs. strong) & 0.396 & $0.140-1.123$ & 0.081 & 0.149 & $0.026-0.843$ & 0.031 \\
\hline EGFR (negative, weak vs. strong) & 0.451 & $0.146-1.387$ & 0.165 & 0.126 & $0.020-0.787$ & 0.027 \\
\hline MVD (<20 vs. $\geq 20)$ & 3.855 & $1.448-10.433$ & 0.007 & 3.040 & $0.904-10.237$ & 0.072 \\
\hline
\end{tabular}

CXCR1/2, C-X-C chemokine receptor types 1/2; OR, odds ratio; 95\% CI, 95\% confidence interval; MVD, microvessel density.

Table VII. Uni- and multivariate analyses of clinicopathological variables and the expression of CXCR $1 / 2$ with regard to N stage.

\begin{tabular}{|c|c|c|c|c|c|c|}
\hline \multirow[b]{2}{*}{ Variables } & \multicolumn{3}{|c|}{ Univariate analysis } & \multicolumn{3}{|c|}{ Multivariate analysis } \\
\hline & OR & $95 \% \mathrm{CI}$ & P-value & OR & $95 \% \mathrm{CI}$ & P-value \\
\hline CXCR1/2 (negative, weak vs. strong) & 23.571 & 7.121-77.945 & $<0.001$ & 29.108 & $5.807-146.057$ & $<0.001$ \\
\hline pERK (negative, weak vs. strong) & 5.155 & $1.910-13.902$ & 0.001 & 5.523 & $1.283-23.807$ & 0.022 \\
\hline EGFR (negative, weak vs. strong) & 2.983 & $1.012-8.802$ & 0.047 & 7.243 & $1.022-51.367$ & 0.048 \\
\hline VEGF (negative, weak vs. strong) & 0.610 & $0.257-1.449$ & 0.262 & 0.106 & $0.022-0.514$ & 0.005 \\
\hline $\operatorname{MVD}(<20$ vs. $\geq 20)$ & 5.686 & $2.201-14.673$ & $<0.001$ & 6.398 & $1.779-23.035$ & 0.004 \\
\hline
\end{tabular}

CXCR1/2, C-X-C chemokine receptor types 1/2; OR, odds ratio; 95\% CI, 95\% confidence interval; MVD, microvessel density.

believed to be involved in all stages of certain types of cancer, including influencing the tumor microenvironment $(28,29)$, malignant cell survival and growth (30), angiogenesis (28), invasion (31) and metastasis $(10,11,32)$. A greater understanding of the chemokine receptor system in malignancy would not only add to our knowledge of the pathogenesis of cancer, but may also suggest new treatment targets for development. CXCR1/2, members of the chemokine receptor family, have been studied in several types of cancer, showing a close correlation with drug resistance, survival, growth, angiogenesis, invasion and metastasis in breast cancer (16), melanoma (17), pancreatic cancer $(19,33)$ and colon cancer (18). In melanoma, knockdown of the receptors or the use of antagonists or neutralizing antibodies against CXCR $1 / 2$ affected cell proliferation, migration and tumor growth, strongly indicating the involvement of these receptors in melanoma progression (34).

In gastric carcinoma there is little information concerning the expression of CXCR $1 / 2$ proteins, which are generally believed to play a role in tumor progression by interacting with their ligands. In the present study, we examined CXCR $1 / 2$ protein expression in gastric carcinoma, and CXCR $1 / 2$ expression was immunohistochemically detected in 68 (98.6\%) of the 69 tumor specimens. The expression level of CXCR1/2 was higher in gastric carcinoma than in the corresponding non-neoplastic mucosa in certain cases.

Previous studies have indicated that CXCR $1 / 2$ expression is significantly correlated with invasion, metastasis and advanced TNM stage in patients with malignant mela- noma (35) and prostate cancer (36). Our current data show that the membrane and cytoplasmic expression of CXCR $1 / 2$ in gastric carcinoma cells was positively correlated with advanced $\mathrm{T}$ stage, $\mathrm{N}$ stage and overall TNM stage. $\mathrm{T}$ stage and $\mathrm{N}$ stage represent invasion and metastasis degree, respectively (22). These data indicate that CXCR $1 / 2$ may be involved in the invasion and metastasis of gastric carcinoma. Univariate and multivariate analysis revealed that strong CXCR 1/2 expression was a significant risk factor for $\mathrm{T}$ stage, $\mathrm{N}$ stage and TNM stage, from which CXCR $1 / 2$ expression appears to play an overlooked role in the development and progression of gastric carcinoma, as does MVD. Our findings further support the hypothesis that there is an association between CXCR1/2 expression and cancer cell invasion and metastasis in certain cancer types $(14,16,37,38)$.

Several studies have indicated that chemokine receptors play multiple roles in the development and progression of a number of tumors via various mechanisms $(14,39-42)$. To investigate the possible mechanisms of CXCR $1 / 2$ involvement in the progression of gastric carcinoma, we examined the immunohistochemical expression of ERK1/2 and AKT phosphorylation and the expression of relevant indicators of proliferation, growth and apoptosis (Bcl-2 and Bax, Cyclin D1, EGFR and Ki-67), angiogenesis (VEGF and CD34), invasion and metastasis (MMP-9, MMP-2, TIMP-2 and E-cadherin) in primary gastric carcinoma and its corresponding nonneoplastic mucosa, which were involved in the regulation of tumor proliferation, growth, angiogenesis, invasion and metas- 
tasis. Evaluation of the correlation between the expression of CXCR1/2 and the indicators using the Spearman correlation analysis revealed that CXCR1/2 expression was positively correlated with Cyclin D1, EGFR, Bcl-2, MVD, MMP-9 and MMP-2. CD34 is a marker of MVD and reflects angiogenesis, which plays an important role in the growth and invasion of tumors (43). The cell cycle regulatory protein Cyclin D1 may contribute to TNM classification, histological differentiation, perineural invasion, DNA ploidy, S-phase fraction, expression of Ki-67 and mitotic index. EGFR has been shown to be associated with tumor proliferation and growth, Bcl-2 inhibits tumor apoptosis and MMP-9 and MMP-2 play an indispensable role in tumor invasion and metastasis $(44,45)$. Based on our results, it is possible that via the upregulation of Cyclin D1, EGFR, Bcl-2, MMP-9 and MMP-2 expression and MVD, CXCR1/2 and their ligands are involved in mediating proliferation, growth, angiogenesis, invasion and metastasis of gastric carcinoma.

Other studies $(14,15)$ have found that abnormal phosphorylation of ERK1/2 and AKT was closely associated with proliferation, growth, angiogenesis, invasion and metastasis of tumors, and played as an intermediary between CXCR1/2 and their downstream molecular indicators. Following stimulation of CXCR1/2 receptors with the ligands, for example IL-8, heterotrimeric small $\mathrm{G}$ proteins are activated and promote the activation of the primary effector, such as phosphatidyl-inositol3-kinase, one of the principal targets of the CXCR1/2 subunits. Activation of the phosphatidyl-inositol-3-kinase may result in increased phosphorylation of its substrate serine/threonine kinase, PKB/AKT (46), promoting the activation of AKT or MAPK signaling cascades. These signaling pathways have been shown to promote protein translation and regulate the activity of a range of transcription factors, and are likely to induce the transcription of multiple genes involved in angiogenesis, cell cycle regulation, migration, invasion and the evasion of apoptosis (14). Increased AKT expression and activity by CXCR $1 / 2$ receptor/ ligand signaling have been detected in multiple forms of cancer, which is consistent with poor tumor progression (47). A study conducted by one group suggests that $\mathrm{CXCR} 1 / 2$ receptor/ligand signaling not only induces activation of AKT but also increases the expression of AKT in androgen-independent prostate cancer cell lines (48). The CXCR1/2 receptor/ligand pathway also regulates the activity of the activation of MAPK signaling cascade, with downstream phosphorylation of ERK1/2 detected in cancer cells (48-50). Certain studies conducted in ovarian and lung cancer cell lines showed that the $\mathrm{CXCR} 1 / 2$ receptor/ligand pathway transactivates EGFR, promoting the downstream activation of MAPK signaling and mediating cell proliferation and survival $(49,50)$. Our data showed that strong CXCR1/2 expression was positively associated with the phosphorylation of AKT and ERK. Further analysis indicated that the expression of pAKT was significantly correlated with Ki-67, EGFR, Bcl-2, VEGF and MMP-2 expression, and pERK expression was significantly correlated with Ki-67, EGFR, Bcl-2, MMP-9 and MMP-2 expression and tended to correlate with Cyclin D1, Bax, MVD and TIMP-2 expression. Therefore, these results, to a certain extent, suggest that CXCR1/2 receptor/ligand signaling plays a significant role in the progression of gastric carcinoma by means of ERK1/2 and AKT phosphorylation, two important pathways (Fig. 3).
In conclusion, the results of the current study suggest that the overexpression of CXCR1/2 was associated with the malignant progression of gastric carcinoma, and simultaneously with the expression of certain indicators of phosphorylation, proliferation, growth, apoptosis, angiogenesis, invasion and metastasis. It is possible that CXCR1/2, interacting with their ligands, activate ERK1/2 and AKT phosphorylation, which in turn mediates the expression of indicators of proliferation, growth, apoptosis, angiogenesis, invasion and metastasis; and activation of the signaling pathway results in poor progression of gastric carcinoma (Fig. 3). Therefore, CXCR1/2 may be a useful predictive marker and promising therapeutic target in gastric carcinoma. Further research is required to confirm the relevance of CXCR1/2 expression to gastric carcinoma progression in vitro and in vivo.

\section{Acknowledgements}

This study was partially supported by the Hunan Provincial Innovation Foundation For Postgraduates (No. CX2011B046), the Graduate Degree Thesis Innovation Foundation of Central South University (No. 2009ssxt062), the Science and Technology Program Foundation of Changsha City (Nos. K1005005-31 and K1106041-31), the Open-end Fund for the Valuable and Precision Instruments of Central South University, the Key Program of Natural Science Fund of Hunan Province (No. 09JJ3040) and the National Natural Science Fund of China (No. 81001080).

\section{References}

1. Ferlay J, Shin HR, Bray F, Forman D, Mathers C and Parkin DM: GLOBOCAN 2008 v2.0, Cancer Incidence and Mortality Worldwide: IARC CancerBase No. 10 [Internet]. Lyon, France: International Agency for Research on Cancer; 2010. http:// globocan.iarc.fr, accessed on February 27, 2012.

2. Alberts SR, Cervantes A and van de Velde CJ: Gastric cancer: epidemiology, pathology and treatment. Ann Oncol 14 (Suppl 2): ii31-36, 2003

3. Yang L: Incidence and mortality of gastric cancer in China. World J Gastroenterol 12: 17-20, 2006.

4. Hyung WJ, Noh SH, Yoo CH, et al: Prognostic significance of metastatic lymph node ratio in T3 gastric cancer. World J Surg 26: 323-329, 2002

5. Balkwill $\mathrm{F}$ and Mantovani A: Inflammation and cancer: back to Virchow? Lancet 357: 539-545, 2001.

6. Nathan C and Ding A: Nonresolving inflammation. Cell 140: 871-882, 2010.

7. Mantovani A: Cancer: Inflaming metastasis. Nature 457: 36-37, 2009.

8. Righi E, Kashiwagi S, Yuan J, et al: CXCL12/CXCR4 blockade induces multimodal antitumor effects that prolong survival in an immunocompetent mouse model of ovarian cancer. Cancer Res 71: 5522-5534, 2011

9. Wendel C, Hemping-Bovenkerk A, Krasnyanska J, et al: CXCR4/ CXCL12 participate in extravasation of metastasizing breast cancer cells within the liver in a rat model. PLoS One 7: e30046, 2012.

10. Balkwill FR: The chemokine system and cancer. J Pathol 226: 148-157, 2012.

11. Lazennec G and Richmond A: Chemokines and chemokine receptors: new insights into cancer-related inflammation. Trends Mol Med 16: 133-144, 2010.

12. Murphy PM: The molecular biology of leukocyte chemoattractant receptors. Annu Rev Immunol 12: 593-633, 1994.

13. Kelvin DJ, Michiel DF, Johnston JA, et al: Chemokines and serpentines: the molecular biology of chemokine receptors. J Leukoc Biol 54: 604-612, 1993.

14. Waugh DJ and Wilson C: The interleukin- 8 pathway in cancer. Clin Cancer Res 14: 6735-6741, 2008. 
15. Zhang Y, Wang L, Zhang M, Jin M, Bai C and Wang X: Potential mechanism of interleukin-8 production from lung cancer cells: an involvement of EGF-EGFR-PI3K-Akt-Erk pathway. J Cell Physiol 227: 35-43, 2012.

16. Ginestier C, Liu S, Diebel ME, et al: CXCR1 blockade selectively targets human breast cancer stem cells in vitro and in xenografts. J Clin Invest 120: 485-497, 2010.

17. Singh S, Nannuru KC, Sadanandam A, Varney ML and Singh RK: CXCR1 and CXCR2 enhances human melanoma tumourigenesis, growth and invasion. Br J Cancer 100: 1638-1646, 2009.

18. Varney ML, Singh S, Li A, Mayer-Ezell R, Bond R and Singh RK Small molecule antagonists for CXCR2 and CXCR1 inhibit human colon cancer liver metastases. Cancer Lett 300: 180-188, 2011.

19. Matsuo Y, Raimondo M, Woodward TA, et al: CXC-chemokine/ CXCR2 biological axis promotes angiogenesis in vitro and in vivo in pancreatic cancer. Int J Cancer 125: 1027-1037, 2009.

20. Eck M, Schmausser B, Scheller K, Brändlein S and MüllerHermelink HK: Pleiotropic effects of CXC chemokines in gastric carcinoma: differences in CXCL8 and CXCL1 expression between diffuse and intestinal types of gastric carcinoma. Clin Exp Immunol 134: 508-515, 2003.

21. Wang JP, Hu WM, Wang KS, et al: Upregulation of C-X-C chemokine receptor type 1 expression is associated with latestage gastric adenocarcinoma. Exp Ther Med 4: 55-60, 2012.

22. Washington K: 7th edition of the AJCC cancer staging manual: stomach. Ann Surg Oncol 17: 3077-3079, 2010.

23. Allred DC, Harvey JM, Berardo M and Clark GM: Prognostic and predictive factors in breast cancer by immunohistochemical analysis. Mod Pathol 11: 155-168, 1998.

24. Harvey JM, Clark GM, Osborne CK and Allred DC: Estrogen receptor status by immunohistochemistry is superior to the ligandbinding assay for predicting response to adjuvant endocrine therapy in breast cancer. J Clin Oncol 17: 1474-1481, 1999.

25. Raman D, Baugher PJ, Thu YM and Richmond A: Role of chemokines in tumor growth. Cancer Lett 256: 137-165, 2007.

26. Ali S and Lazennec G: Chemokines: novel targets for breast cancer metastasis. Cancer Metastasis Rev 26: 401-420, 2007.

27. Vindrieux D, Escobar P and Lazennec G: Emerging roles of chemokines in prostate cancer. Endocr Relat Cancer 16: 663-673, 2009.

28. Orimo A, Gupta PB, Sgroi DC, et al: Stromal fibroblasts present in invasive human breast carcinomas promote tumor growth and angiogenesis through elevated SDF-1/CXCL12 secretion. Cell 121: 335-348, 2005

29. Colmone A, Amorim M, Pontier AL, Wang S, Jablonski E and Sipkins DA: Leukemic cells create bone marrow niches that disrupt the behavior of normal hematopoietic progenitor cells. Science 322: 1861-1865, 2008.

30. Singh S, Varney M and Singh RK: Host CXCR2-dependent regulation of melanoma growth, angiogenesis, and experimental lung metastasis. Cancer Res 69: 411-415, 2009.

31. Kitamura T, Kometani K, Hashida H, et al: SMAD4-deficient intestinal tumors recruit CCR1+ myeloid cells that promote invasion. Nat Genet 39: 467-475, 2007.

32. Buonamici S, Trimarchi T, Ruocco MG, et al: CCR7 signalling as an essential regulator of CNS infiltration in T-cell leukaemia. Nature 459: 1000-1004, 2009.

33. Maxwell PJ, Gallagher R, Seaton A, et al: HIF-1 and NF-kappa B-mediated upregulation of CXCR1 and CXCR2 expression promotes cell survival in hypoxic prostate cancer cells. Oncogene 26: 7333-7345, 2007.

34. Varney ML, Li A, Dave BJ, Bucana CD, Johansson SL and Singh RK: Expression of CXCR1 and CXCR 2 receptors in malignant melanoma with different metastatic potential and their role in interleukin-8 (CXCL-8)-mediated modulation of metastatic phenotype. Clin Exp Metastasis 20: 723-731, 2003.
35. Varney ML, Johansson SL and Singh RK: Distinct expression of CXCL8 and its receptors CXCR 1 and CXCR2 and their association with vessel density and aggressiveness in malignant melanoma. Am J Clin Pathol 125: 209-216, 2006.

36. Murphy C, McGurk M, Pettigrew J, et al: Nonapical and cytoplasmic expression of interleukin-8, CXCR1, and CXCR2 correlates with cell proliferation and microvessel density in prostate cancer. Clin Cancer Res 11: 4117-4127, 2005.

37. Müller A, Homey B, Soto H, et al: Involvement of chemokine receptors in breast cancer metastasis. Nature 410: 50-56, 2001.

38. Tanaka T, Bai Z, Srinoulprasert Y, Yang BG, Hayasaka H and Miyasaka M: Chemokines in tumor progression and metastasis. Cancer Sci 96: 317-322, 2005.

39. Koizumi K, Hojo S, Akashi T, Yasumoto K and Saiki I: Chemokine receptors in cancer metastasis and cancer cellderived chemokines in host immune response. Cancer Sci 98: 1652-1658, 2007.

40. Balakin KV, Ivanenkov YA, Tkachenko SE, Kiselyov AS and Ivachtchenko AV: Regulators of chemokine receptor activity as promising anticancer therapeutics. Curr Cancer Drug Targets 8: 299-340, 2008.

41. Ruffini PA, Morandi P, Cabioglu N, Altundag K and Cristofanilli M: Manipulating the chemokine-chemokine receptor network to treat cancer. Cancer 109: 2392-2404, 2007.

42. Kakinuma T and Hwang ST: Chemokines, chemokine receptors, and cancer metastasis. J Leukoc Biol 79: 639-651, 2006.

43. Gabellini C, Trisciuoglio D, Desideri M, et al: Functional activity of CXCL8 receptors, CXCR1 and CXCR2, on human malignant melanoma progression. Eur J Cancer 45: 2618-2627, 2009.

44. Roomi MW, Monterrey JC, Kalinovsky T, Rath M and Niedzwiecki A: Comparative effects of EGCG, green tea and a nutrient mixture on the patterns of MMP-2 and MMP-9 expression in cancer cell lines. Oncol Rep 24: 747-757, 2010.

45. Roomi MW, Monterrey JC, Kalinovsky T, Rath M and Niedzwiecki A: Patterns of MMP-2 and MMP-9 expression in human cancer cell lines. Oncol Rep 21: 1323-1333, 2009.

46. Knall C, Worthen GS and Johnson GL: Interleukin 8-stimulated phosphatidylinositol-3-kinase activity regulates the migration of human neutrophils independent of extracellular signal-regulated kinase and p38 mitogen-activated protein kinases. Proc Natl Acad Sci USA 94: 3052-3057, 1997.

47. Cheng GZ, Park S, Shu S, et al: Advances of AKT pathway in human oncogenesis and as a target for anti-cancer drug discovery. Current Cancer Drug Targets 8: 2-6, 2008.

48. MacManus CF, Pettigrew J, Seaton A, et al: Interleukin-8 signaling promotes translational regulation of cyclin D in androgen-independent prostate cancer cells. Mol Cancer Res 5: 737-748, 2007.

49. Venkatakrishnan G, Salgia R and Groopman JE: Chemokine receptors CXCR-1/2 activate mitogen-activated protein kinase via the epidermal growth factor receptor in ovarian cancer cells. J Biol Chem 275: 6868-6875, 2000.

50. Luppi F, Longo AM, de Boer WI, Rabe KF and Hiemstra PS: Interleukin-8 stimulates cell proliferation in non-small cell lung cancer through epidermal growth factor receptor transactivation. Lung Cancer 56: 25-33, 2007. 